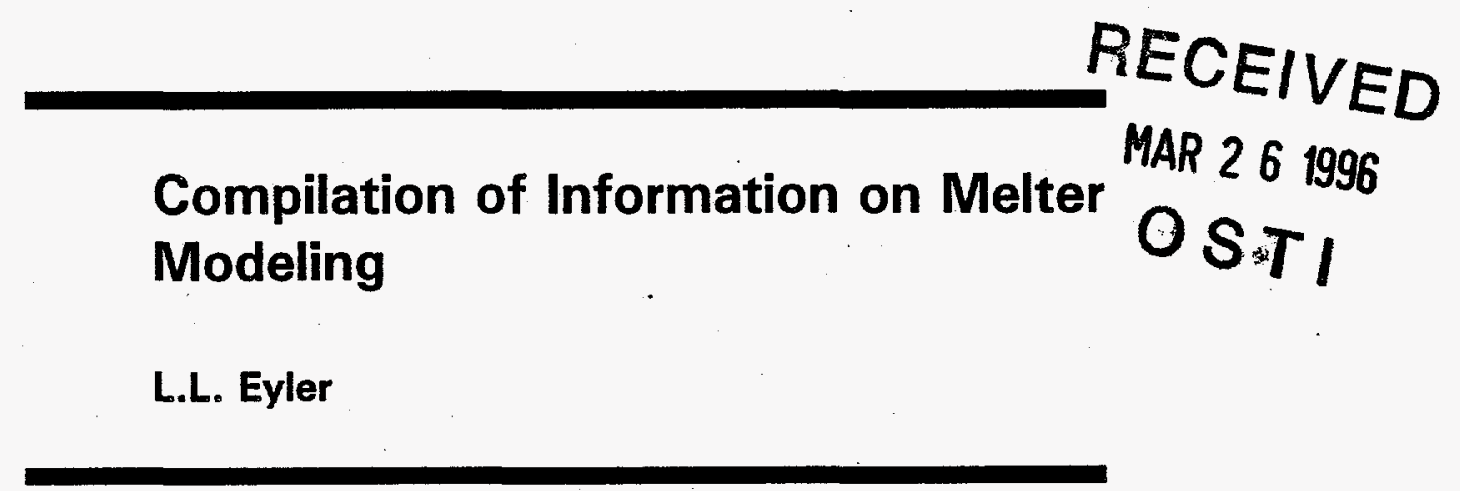

March 1996

Prepared for the U.S. Department of Energy under Contract DE-AC06-76RLO 1830

Pacific Northwest National Laboratory Operated for the U.S. Department of Energy by Battelle Memorial Institute 
PNNL-11015

$\mathrm{UC}-8+102000$

Project Technical Information

\title{
Compilation of Information on Melter Modeling
}

\author{
L. L. Eyler
}

March 1996

Prepared for

the U.S. Department of Energy

under Contract DE-AC06-76RLO 1830

Pacific Northwest National Laboratory

Richland, Washington 99352

Reprint of historical document PVTD-C95-03.01C1 Part A, transmitted with cover letter dated September 6, 1995. Data, formatting, and other conventions reflect standards at the original date of printing. Technical peer reviews and editorial reviews may not have been performed. 


\title{
DISCLAIMER
}

This report was prepared as an account of work sponsored by an agency of the United States Government. Neither the United States Government nor any agency thereof, nor Battelle Memorial Institute, nor any of their employees, makes any warranty, express or implied, or assumes any legal liability or responsibility for the accuracy, completeness, or. usefulness of any information, apparatus, product, or process disclosed, or represents that its use would not infringe privately owned rights. Reference herein to any specific commercial product, process, or service by trade name, trademark, manufacturer, or otherwise does not necessarily constitute or imply its endorsement, recommendation, or favoring by the United States Government or any agency thereof, or Battelle Memorial Institute. The views and opinions of authors expressed herein do not necessarily state or reflect those of the United States Government or any agency thereof.

\author{
PACIFIC NORTHWEST NATIONAL LABORATORY \\ operated by \\ BATTELLE \\ for the \\ UNITED STATES DEPARTMENT OF ENERGY \\ under Contract DE-AC06-76RLO 1830
}

Printed in the United States of America

Available to DOE and DOE contractors from the

Office of Scientific and Technical information, P.O. Box 62, Oak Ridge, TN 37831;

prices available from (615) 576-8401.

Available to the public from the National Technical Information Service,

U.S. Department of Commerce, 5285 Port Royal Rd., Springfield, VA 22161 
Milestone:

C95-03.01Cl

Part A.

\title{
COMPILATION OF INFORMATION ON MELTER MODELING
}

\author{
L. L. Eyler
}

\section{INTRODUCTION}

\section{Objective}

The objective of this task is to compile information on modeling capabilities for the HighTemperature Melter and the Cold Crucible Melter and issue a modeling capabilities letter report summarizing existing modeling capabilities. The report is to include strategy recommendations for future modeling efforts to support the High Level Waste (HLW) melter development. Additional information on inductively heated Cold Crucible Melter modeling capabilities is to be presented in another phase report within this task.

\section{Approach}

The approach used to accomplish the objective includes three main functions. These are:

1. Conduct a literature search for recent publications which address pertinent aspects of melter modeling.

2. Contact commercial glass manufacturers and glass technical services organizations to obtain information on their capabilities.

3. Contact commercial computer software companies to obtain information about past applications of their software in this area and potential applications based on advertised capabilities and user experience.

In addition to the information obtained in these three functions, knowledge and past experience in use of the TEMPEST computer program in the Hanford Waste Vitrification Project (HWVP) Melter Performance Assessment (MPA) provided another important source of information.

The plan is to obtain the information, to review and analyze the information for applicability, and to draw conclusions and make strategy recommendations for future modeling efforts to support HLW melter development.

\section{Modeling Needs}

Modeling of $\mathrm{HLW}$ glass melters requires certain basic capabilities as well as the ability to address certain specific physics particular to processes occurring in the melter. Basic solution capabilities requirements include coupled flow, heat, and constituent transfer and an electric field solution model to calculate Joule heating distributions. Boundary conditions appropriate to the cold cap and the exterior of the melter system are required. These must include boundary conditions appropriate to the flow (melt source and pouring), thermal (cold cap and system exterior), constituent (particulates), and electric field (alternating current source) solutions. Because of the cold cap and the internal Joule heating, the melt pool is physically unstable. This 
leads to a requirement that transient analysis capability is required for most analyses.

The need to model specific physics processes particular to a HLW melter is dependent on several things; including the analysis objectives. There is an obvious need to be able to couple the effects of the solution equations through property dependencies. The principal property effects are through density, thermal conductivity, viscosity, and electric conductivity, all of which may be functions of temperature and constituent (particulate) distributions. To pursue more advanced analyses leading to production rate or glass quality, additional requirements may dictate the need for more specialized idealizations and development of solution approaches.

\section{CONCLUSIONS AND STRATEGY RECOMMENDATIONS}

Several conclusions can be made from the information which has been gathered to date and a strategy can be recommended to pursue computer modeling of HLW glass melters.

\section{Conclusions}

- Computer modeling of melters has advanced rapidly in recent years in both the waste vitrification and commercial glass melter areas. They are an integral and necessary component of design analysis and complement other analysis methods such as physical and scale modeling. Once validated, computer model offers cost advantages over some experimental testing.

- Commercial computer codes have reached a useful state of development and applicability, but require a significant investment in a learning curve and use of user-developed subroutines to adequately implement necessary physics submodels for aspects of HLW melter operation and analyses.

- In a recent international round robin benchmark test, TEMPEST results were well within the standard deviation of 17 other computer simulation results of a well defined, simplistic representation of a commercial glass melter. The submittals included commercial software results and results computed with computer codes specifically designed to simulate melter pool flow and heat transfer characteristics. Several codes reportedly had difficulty in convergence.

- Numerous advances have been made in recent years in modeling effects of bubbles, particulate melting, redox distribution, cording, and batch layer effects in commercial glass melters. These improvements and modeling approaches may be applicable to HLW melters analysis, but will require investments to be made to dig into details, confirm applicability, and complete validation.

- TEMPEST electric field solution methodology is one of the most sophisticated available for multi-electrode, multi-phase, arbitrary wave form solution and prediction of joule heat distribution.

- Quality radiation models are available in several commercial software codes. Applicability of the models needs to be further confirmed, especially in application to clear glasses such as are postulated for some low level wastes (LLW).

- A strategy plan needs to be developed for applying further computer analyses to HLW 
melters that clearly defines analysis needs, results objectives, and validation approach.

\section{Strategy Recommendations}

To further advance modeling of HLW glass melters, a strategy plan needs to be formulated that has specific goals of analysis and specific goals of validation of computations. Computer modeling of melters, both $\mathrm{HLW}$ and commercial melters, has reached a state where the basic processes of buoyancy-driven, highly viscous, flow and heat transfer in the melt pool can be predicted reasonably well with transient computational capabilities. Conjugate heat transfer in adjacent refractory materials can be well coupled by some analysis tools. In commercial glass melter modeling, most recent advances have been in attempting to address modeling of processes that affect glass quality and production. These include for example, gas bubbles, particle transport and melt rates, redox distribution, cording, and batch-layer melting processes. Currently available analysis capabilities have been well demonstrated in HLW melters in recent HWVP Melter Performance Analysis (MPA) work (Elliott et al (1); Grünewald et al (2); Cooper et al (3)) . Thus, a strategy for advancing glass melter modeling needs to be formed that accepts the current state of analysis and builds upon it (develops additional capabilities) that are designed to address additional processes in the melter that affect operation and production, solids loading, and glass quality.

Any strategy forward needs to acknowledge that no software tool that exists today will satisfy all analysis requirements. Commercial glass manufacturers that use commercial software tools invest significant resources in applying and modifying the tools through the use of userdefined routines. Extensive investments have been made in proprietary tools. Some of this knowledge may be transferrable to HLW melters, but acquiring it for beneficial use may be difficult. Commercial software regularly over-state applicabilities through use of pretty color promotions. Actual users find that commercial tools may not perform up to expectations and that application-specific modifications can be cumbersome, extensive, and difficult to track user routine usage for quality assurance (QA) purposes. A strategy forward using commercial software must account for the learning curve and application-specific development needs in user routines.

A strategy forward should acknowledge that TEMPEST has been successfully applied to HLW melters through the HWVP MPA. TEMPEST has advantages over other tools in its electric field solution capabilities and in its developed capabilities for coupling effects of particulate material (most specifically noble metals effects). Another advantage to TEMPEST is that complete access to source code is available on-site for both generic and model-specific modification.

Validation and QA requirements must also be addressed. A continuing validation strategy needs to be developed. The strategy needs to address validation of numerics and solution approximations as well as sub-model physics, and coupled application analyses. This is necessary to continue assuring quality results, independent of choice of computer analysis tool. Additional laboratory scale experiment tests may be necessary to support validation requirements of certain sub-models. Continued participation in international modeling forums such as recent involvements with the round robin test of melter modeling conducted in Europe. A similar forum could be developed between US commercial glass melter manufacturers, commercial software vendors, government laboratories, and HLW melter contractors as a method of pooling resources and capabilities. 


\section{LITERATURE}

A literature search was conducted to identify recent advancements in meiter modeling. Literature reviewed are contained in the subsequent sections titled References - Cited and References - Reviewed. Cited literature are referenced here after with a number in parentheses (). Reviewed literature are background information from which general observations about capabilities are taken. They are not specifically cited.

Three publications were found to be particularly pertinent and useful. A review of the state-of-the-art, availability, and uses of physical and mathematical modeling of furnaces was conducted by Venkateswaran and Conrad and was published in 1990 by the Electric Power Research Institute (EPRD) Center for Materials Production (4). Viskanta (5) presented a review of three-dimensional mathematical modeling of glass melting at a glass processing symposium in 1993. Wooley (6) presented a short course on glass melting process in 1994 and made extensive reference to modeling aspects. While all three of these overviews were focused on glass melting processes and furnaces for commercial glass, many of melt pool characteristics are relatable to HWVP vitrification melters, especially those furnaces which are electrically heated or electrically boosted.

The objective of the EPRI Center for Materials Production (CMP) report (4) was to prepare a compilation and review of the modeling services available to the glass industry, assess the capabilities of these models, and to identify areas for possible improvement and further development of modeling. The report found that earliest models dating to the 1930s, were physical models. Mathematical models were begun in the late 1960s and focused on characterizing on flows and heat transfer in melters. Greater computer power led to three-dimensional models in the 1980s. The largest concentration of modeling capabilities lies within the large glass manufacturers, who use modeling for designing new furnaces, evaluating design changes, and optimizing furnace operation. Many universities have strong capabilities in mathematical modeling of flow, heat transfer, and electric fields. Additionally, various research organizations were found to have done extensive physical and mathematical modeling of electrical melters in support of the nuclear waste vitrification programs, including the Pacific Northwest Laboratory. The report identifies several areas for further development emphasizing mathematical models because they have more complete modeling capability, are more predictive in nature, and are expected to predominate modeling in the future. The report presents a concise tabulation of modeling capabilities by organization, a tabulation of users of models, and lists 126 references. For a tabulation of modeling capabilities by organizations, see this EPRI Center for Materials Production report by Venkateswaran and Conrad (4).

The paper by Viskanta (5) is more current and more focused towards three-dimensional mathematical modeling. He is with the Heat Transfer Laboratory at Purdue University; and both he and the school are well known for their capabilities of modeling glass furnaces. His paper presents incentives of simulating flow patterns and heat transfer in the melt pool, model idealization, input data needs, and desired outputs. He presents a review of advantages and disadvantages of modeling and concludes with identification of remaining challenges which include effective presentation of immense amounts of computer generated data and interpretation of results for the purpose of improving glass quality and productivity. An orderly review is made of historical advances and the most pertinent physics (model idealizations) including effects of bubbles, design and operation parameters, electric boosting, degassing and redox distribution, and solution algorithm. A list of the most pertinent reasons for disagreement between predictions and data is presented. Included in this list are unreliable thermophysical, transport, and radiative 
properties, effects of gas bubbles and undissolved batch, and inaccuracies in submodels. The paper includes several example computational results and 54 references.

Wooley's short course notes (6) encompasses many aspects of glass melting process and contain numerous references to need, use, requirements, and applicability of mathematical modeling to glass melting. He addresses transport process in glass tanks including the effects of chemical reaction kinetics, momentum boundary layer diffusion limits, inertial effects, viscosity gradients, and radiative heat transfer. In electric heating, he considers electrical conductivity, thermal instabilities, and near-electrode effects in modeling approach considerations. Discussions are presented of model approaches to bubbles, volatilization, diffusion and stirring (convection), and batch. In discussing electric melters, he discusses design and operating considerations. He also discusses the advantages and disadvantages of electric melting. In reviewing simulation of melters (modeling), he reviews available capabilities and states that more modeling effort is now devoted to computer modeling because of its 10 -fold cost advantage and the rapidly increasing capability to handle complex cases. Present efforts, both industrial and academic, are directed towards developing more efficient numerical methods, more realistic models of the batch layer and combustion space, and better integration of the thermochemical models, gas exchange models, and grain dissolution models. Such integrated models are starting to be used to predict the overall effect on glass quality. He concludes that validation is the principal weakness of modeling today. Over 100 references encompassing the glass melting processes are included.

The reader should see the References - Reviewed section for papers from which qualitative observations about the state of modeling of glass melting are drawn.

\section{GLASS COMPANY MODELING CAPABILITIES REVIEW}

\section{Industrv/Research and Development (R\&D) Organizations}

Several industry and research and development organizations have glass tank flow models. The heart of these models is a 3-dimensional (3-D) model which solves the simultaneous differential equations of continuity, flow, and heat transfer. Many of these also solve the equations for the electric field. These models generally use finite difference techniques, but can also use finite element or finite volume techniques. These main flow models give velocity and temperature distributions throughout a glass tank. However, the goal in glass tank modeling is often to obtain information regarding glass quality, or possibly optimize for energy efficiency or environmental concerns. To do this, extra information is needed, which is obtained via submodels, which are coupled to the flow model, or post processing models. Examples of these submodels or postprocessing models include reactions in the batch, volatilization, bubble growth and shrinkage, etc. While the main flow models used in most of the organizations described below are similar and use similar assumptions, the capabilities of the submodels vary.

The capabilities of industry and R\&D organizations are summarized below. In many cases, more detailed information cannot be obtained due to its proprietary nature.

\section{Corning Incorporated Process Modeling Group}

Glass melter modeling capabilities at Coming have changed significantly since about 1990. Corning has available a 3-D steady state model which solves the equations for flow, heat transfer and power dissipation. For rectangular or cylindrical melter geometries, an in-house code is used 
which is based on SIMPLER methodology (early 1980's technology). For more complex geometries or for modeling combusting flows, they use the commercial computational fluid dynamics (CFD) package FLUENT. The glass melt model can be interfaced with a crown model which predicts the glass bath surface heat flux distribution for given fuel/oxidant flows in combustion melters. A fining submodel is also available to track bubble behavior (growth and shrinkage) which affects glass quality and is an important issue in the glass manufacturing industry. Standard residence time distribution calculations can be performed as well.

Corning has done some work in modeling radiative transfer in the melt, avoiding the Rosseland approximation (effective thermal conductivity). This has not been completed, however. Their opinion is that with an optically thick glass such as waste glass, using effective thermal conductivity to account for radiant heat transfer is adequate. Corning has had experience modeling all electric (single or three-phase) melters as several of Corning's melters are now electric.

Detailed information about Corning's models is considered proprietary and is not available in published papers. However, calculations can be and are performed as a service for outside customers.

\section{TNO Institute of Applied Physics The Netherlands}

The Institute of Applied Physics TPD-TNO is part of the Netherlands Organization for Applied Scientific Research. TNO is a fully independent R\&D organization and has conducted research in glass technology for over 40 years. The glass department has a staff of 17 , including physicists, and chemical and mechanical engineers.

TNO has extensive capabilities in the modeling of glass furnaces. Their 3-D model solves the mass, momentum, and energy equations by a finite difference method. Finite element techniques can be used for complex geometries. Numerous submodels can be used and integrated with the flow model, including ones for batch blanket rheology and melting, combustion space heat transfer, forced bubbling, dissolution of sand grains, and gas and redox distribution in the melt. The results from the flow model and submodels are used to calculate indices that represent glass quality, including: melting index, refining index, homogenization index, amount of undissolved raw material in the end product, and amount of bubbles in the end product.

TNO has modeled all-electric melters. Electrical heating using immersed or wall electrodes is calculated by solving the real and imaginary parts of the potential field. Almost any electrode set-up can be modeled.

TNO can be contracted to perform calculations using their model or the software can be purchased from TNO with their approval. Ten glass companies currently use TNO's glass tank model.

3. Ford Glass

K.K. Koran 1-313-390-2053

A request for information generated no response.

4. Owens-Corning Fiberglass

Max Chrisman

Manoj Choudhary 1-614-321-7568 


\section{Quey Tsay}

Owens-Corning uses an in-house model, which was developed in the 1980's and has been described in published papers. The model uses finite difference techniques to solve the mass, momentum and energy transfer equations. Flow problems are formulated and solved in terms of the primitive variables (velocity components and pressure). Radiative heat transfer is accounted for through an effective thermal conductivity.

Owens-Corning has discussed selling services to customers, but has not to date, mainly due to their heavy internal workload and limited time.

5. Owens-Illinios
W.A. Poolos 1-419-247-5000

Nothing available for outside customers.

6. Techtronix (formerly AVCO)

J. Woodroffe

They no longer do modeling. A former employee does this independently, but not for electric melters. Name is Ashok Chatwani 1-617-273-3189.

7. KTG Glassworks

"Joe" 1-412-366-0330

Physical modeling only.

8. Technical Committee \#21

Dr. W. Muschick, Chairman

SCHOTT Glaswerke Mainz

FAX 496131664012

The International Committee on Glass (ICG) formed a technical committee (TC\#21) in 1990 to investigate melter modeling. The committee recently conducted a round robin test to evaluate numerical modeling of a well-defined albeit simplified model of a commercial glass melter. A total of 18 committee member organizations and guest organizations from all over the world participated in the round robin test. Computed results obtained using commercial software packages and private organization developed software were submitted. Pacific Northwest Laboratory (PNL) submitted results computed with TEMPEST.

A preliminary set of comparison results were received and several observations were worth noting. The defined conditions of the benchmark test, by standards of comparison to a real operating melter, were very straight forward. Fixed temperature top surface boundary conditions and fixed side wall heat flux were specified. Even so, the preliminary report of results indicated that problem conditions had to be change because several codes had convergence difficulties. Direct comparison of results at specified locations indicated that a wide range of values were predicted for the local flow character, but in general, the basic characteristics (recirculation) of the flow field were quite similar. The condition and presence of the batch layer had the most dominant influence. The location of the "mechanical" spring was very close to the back wall coupled with the relatively coarse grid resolution and data reduction technique probably led to the wide variation in predicted position. Of the data compared at specific locations, TEMPEST results were within 
the standard deviation of all model results. No computer time (Central Processor Utilization, or CPU) requirements were reported with the results, but computationally, TEMPEST had no difficulty in modeling this problem.

\section{British Glass Technology Sheffield, S10 2UA}

British Glass provides consulting services to the glass industry world-wide. They are also engaged in R\&D. British Glass has a CFD package which is used for glass modelling purposes. Judging from the available information, it does not appear this is a major emphasis area of their work.

\section{COMPUTER SOFTWARE CAPABILITIES REVIEW}

Computer software that solves fluid flow, heat, and mass transfer has greatly increased in capability in recent years. Software packages exist for a wide range of applications in a wide range of industries. Use of these packages within the glass melter business is a small subset. Computer codes are available in the public and private sector. Software in the public sector has traditionally originated from government organizations and from universities. In the private sector, software falls into two categories - proprietary (internal to an industry) and commercial (software for sale). It is not easy to obtain other than general information about proprietary software - for obvious reasons. Commercial software can, according to salespeople and promotional brochures, do anything. Thus without actually using commercial software for an application, evaluation of applicability has to be tendered through published information (users manuals and technical papers) and personal communication with developers, technical support staff, and other users.

In recent years, with the advent of faster and faster computers, advancing numerical and physical solution capabilities, and improved user interfaces, application of thermal hydraulic computer codes has expanded. Comparative reviews of software capabilities have been done and are available. One such review was published by SiliconGraphics Computer Systems (7). This review tabulates computational fluid dynamics software into four categories: pre-processors and grid generators, flow solvers, post-processors and visualizers, and complete packages. Several of the more prominent software companies listed in the tabulation were contacted to obtain information on the software, its application to glass melter modeling, and users which could be contacted to gain additional information.

Contacts were made with companies that market CFDS FLOW-3D, FLUENT, FIDAP, STAR-CD, CFD 2000, and PATRAN. These are prominent commercial codes with which some familiarity was already known. TEMPEST is a PNL software package that has been used in glass melter modeling for several years within the waste vitrification programs at Hanford. Following is a summary of the codes and information obtained.

TEMPEST is software developed at PNL and applied to a wide variety of fluid and thermal problems; most recently, in the areas of waste glass melter modeling and waste tank safety issues. It is time dependent and is based on finite-volume techniques using orthogonal curvilinear coordinates.

CFDS FLOW-3D marketed by AEA Technology, Computational Fluid Dynamics Services. PNL has a licensed copy of this code. It is a multi-dimensional fluid dynamics code which can solve a wide variety of problems on non-orthogonal grid systems using a finite volume approach. 
FLUENT is marketed by Fluent Incorporated. FLUENT is computational fluid dynamics software based on finite volume approach to discretization. The company also markets NEKTON and RAMPANT, which are more specialized codes based on unstructured and adaptive grid systems.

FIDAP is marketed by Fluid Dynamics International. It is a finite element-based software package.

STAR-CD is marketed by ADAPCO Analysis \& Design Application Co., Ltd. It is a software package based finite volume solution of the governing equations.

CFD 2000 is marketed by Adaptive Research. It is computational fluid dynamics software based on finite volume approach.

PATRAN is marketed by PDA Engineering. This company markets several software packages including P/FLOTRAN which is a finite volume based fluid dynamics solver.

Contact was made with each of these companies and promotional information was obtained, More detailed technical information was available for FLOW-3D, FIDAP, and FLUENT including user manual information. TEMPEST user and theory manuals are also available to this evaluation.

Several fundamental observations can be made regarding the capabilities of these commercial codes to model the melt pool. All of them solve three-dimensional, buoyancy driven, coupled fluid and heat transfer. The coupling of temperature-dependant fluid properties is available. This is straight forward for density, viscosity, and thermal conductivity for normal fluids (air, water, etc.). In the commercial codes, accounting for glass melt properties is allowed through use of user FORTRAN. This is a technique whereby a template is available for a user callable subroutine. The user then programs the subroutine for the particular property dependencies desired. This approach allows users to tailor the analysis to the problem at hand in an environment where source code of the main computer program is not available. An alternate approach has been programmed into TEMPEST for specialized properties. Functional forms of property dependencies have been programmed into the code. The user supplies curve-fit constants to obtain desired properties. TEMPEST source code is available to glass melter modeling if alternate models are necessary. This approach works very well in glass modeling where both temperature and solid particles (constituent fraction) affect properties.

Constituent transport is also solved and a particle tracking method is available. Both methods are potentially applicable to modeling glass melters. In commercial glass melters, the particle tracking method has been used to predict average residence times and to estimate melt rates of batch material. Both methods were investigated as part of the HWVP Melter Performance Assessment modeling task with TEMPEST, and it was concluded that the particle tracking method was not useful in simulating settling particles (noble metals) because particle position variations resulting from slow settling rates of small particles were indiscernible from path integration inaccuracies. Further, computational requirements of a sufficient number of particles to be statistically significant in representing particle-dependent property variations was excessive, particularly in time-dependent analysis.

Thermal radiation is another consideration. Commercial codes and TEMPEST have various radiation models available. For boundary conditions, such as the top surface of the cold 
cap and shining, radiation sink conditions are available. Because HLW glass is black, the Rosseland approximation is made and radiation is included as a component of thermal diffusion through the thermal conductivity data measured for the glass. For this reason, no thermal radiative transport model has been implemented in TEMPEST for use in glass modeling, even though a onedimensional, non-participating thermal radiation model has been programmed. In the commercial codes, more sophisticated thermal radiation models are available, including participating media models for use in optically thick media. This type of thermal radiation modeling is needed for commercially manufactured (clear) glass, and LLW glass may be such a glass also.

Capability of electric field solution is a bit more difficult to evaluate. The multi-field, arbitrary wave-form, phase-angled alternating current electric field model implemented in TEMPEST was developed specifically to address multi-electrode waste glass melters. Commercial computer codes do not advertise electric field solution as a capability. However, users of FIDAP on the Defense Waste Processing Facility (DWPF) melter implemented a DC-approximated electric potential solution to obtain a Joule heat distribution. Another user of FIDAP has used the code to model vitrification using an in-ground melter. This application required coding modification to implement the electric field solution and a Proportional-Integral-Derivative (PID) controller, not unlike that in TEMPEST. This capability is now being advertised as a feature in FIDAP. A communication from FLUENT developers proposed a detailed methodology for utilizing a scalar transport equation to approximate an electric potential solution. This involves solving a scalar transport equation (constituent) with convection turned off and diffusion coefficients appropriately set to reflect electric conductivity in place of species diffusion. Thus, there is some electric field solution capability in some commercial codes, but it is in general, not a feature.

\section{REFERENCES - CITED}

1. M. L. Elliott, L. L. Eyler, et al. 1994. " Preliminary Melter Performance Assessment Report". PNL-9822. Pacific Northwest Laboratory, Richland Washington.

2. Grünewald, W., et al, (KfK) and M. L. Elliott and L. L. Eyler (PNL). 1993. "Vitrification of Noble Metals Containing NCAW Simulant with an Engineering Scale Melter (ESM)". Kernforschungszentrum Karlsruhe (KfK), Germany.

3. M. F. Cooper, M. L. Elliott, L. L. Eyler, et al. 1993. "Research Scale Melter Report". PVTD-K902. Pacific Northwest Laboratory, Richland, WA.

4. Venkateswaran, S. R. and J. L. Conrad. 1990. "Modeling of the Glass Melting Process". CMP Report Number 90-4. Energetics, Incorporated, for the Electric Power Research Institute Center for Materials Production, Carnegie Mellon Research Institute, Pittsburgh, Pennsylvania.

5. Viskanta, R. 1993. "Review of Three-Dimensional Mathematical Modeling of Glass Melting". Paper presented at the Glass Processing and Manufacture Symposium, Hawaii, Nov. 7-10. (To be published in Journal of Non-Crystalline Solids)

6. Woolley, F. E. 1994. "Glass Melting Process". Corning Incorporated, Corning, New York. Notes for a short course presented at Westinghouse Hanford Company, October 17-18.

7. SiliconGraphics, CFD-92, "How to CFD". 2011 North Shoreline Blvd. Mountain View, CA 94043. 


\section{REFERENCES - REVIEWED LITERATURE}

1. A. Ungan and R. Viskanta. Three-Dimensional Numerical Simulation of Circulation and Heat Transfer in an Electrically Boosted Glass Melting Tank. IEEE Transactions on Industry Applications, Vol. IA-22, No. 5, September/October 1986.

[Presents resuits of 3-D modeling of an electrically-boosted combustion melter.]

2. R: Viskanta and $X$. Wu. Effect of radiation on the melting of glass batch. Glastechnische Berichte 56 (1983) Nr. 6/7, s. 138-147.

[Describes model to predict the temperature distribution and teat transfer in a glass batch blanket, including the effects of radiation transfer in the fused batch/molten glass layer and on the melting time of unpreheated and preheated batch.]

3. H. Igarashi and T. Takahashi. A three-dimensional mathematical model for an electric glass melter used to vitrify nuclear high-level liquid waste. Glass Technology, Vol. 32 No. 6 December 1991

[Describes model and results for the liquid-fed joule-heated ceramic melter at the Tokai Vitrification Facility and compares the results with actual operating data.]

4. W.D. Henderson, J.D. Carling and H. Rawson. The experimental determination of the effective thermal conductivity of various glasses over the temperature range 1000-1300C. Glass Technology Vol. 24 No. 3 June 1983.

5. V.K. Shiff. Calculation of the Electric Field in a Glass Making Furnace with Plane Electrodes. Glass and Ceramics V.50(7-8) 1993.

6. M. Nemecek. Temperature fields close to the electrode surface in glass melt. Silikaty C. $3 \mathrm{~s}$. 193-205. 1987.

7. G. Hilbig Three-dimensional analytical model for the straight-through flow in an all-electric glass melting furnace. Glastechnische Berichte 63 Nr. 71990.

8. R. Viskanta Review of Three-Dimensional Mathematical Modelling of Glass Melting. Journal of Non-Crystalline Solids, Vol. 177 p. 347-362 1994.

\section{REFERENCES - PERSONAL COMMUNICATIONS AND TELECOMMUNICATIONS}

\section{Glass Companies}

\section{Corning Incorporated \\ Process Modeling Group \\ Bill W. Johnson 1-607-974-6826 \\ Doug Neilson}


Detailed information about Corning's models is considered proprietary and is not available in published papers. Information was obtained by personal communication and telephone conversations.

2. TNO Institute of Applied Physics

Den Dolech 2, Building SL

P.O. Box 595

5600 AN Eindhoven

The Netherlands

Dr. R.G.C. Beerkens Manager, Glass Technology

Ir. H.P.H. Muysenberg, Project Leader, Mathematical modeling

Phone +3140656400

Fax +31 40449350

Information on TNO was obtained in response to a written letter of request and included promotional information and the following:

Mathematical Modeling of the Glass Melting Process. Prof. dr. ir. H. deWaal, Institute of Applied Physics - TPD/TNO. The Netherlands.

Possibilities of Glass Tank Modeling for the Prediction of the Quality of Melting Processes. Ruud G.C. Beerkens, Tom Van der Heijden, Eric Muijsenberg, TNO. Ceram. Eng. Sci. Proc. 14[3-4] pp.139-160 (1993).

3. Ford Glass

K.K. Koran 1-313-390-2053

A request for information generated no response.

4. Owens-Corning Fiberglass

Max Chrisman

Manoj Choudhary 1-614-321-7568

Quey Tsay

Owens-Corning Fiberglass responded to requests for information published in 1988.

A Three-Dimensional Mathematical Model for Flow and Heat Transfer in Electrical Glass Furnaces. Manoj K. Choudhary. IEEE Transactions on Industry Applications, Vol IA-22, No. 5, September/October 1986.

A Modeling Study of Flow and Heat Transfer in an Electric Melter. Manoj K. Choudhary. Journal of Non-crystalline Solids 101 (1988) 41-53.

5. Owens-Illinios

W.A. Poolos 1-419-247-5000

Nothing available for outside customers.

6. Techtronix (formerly AVCO)

J. Woodroffe 
They no longer do modeling. A former employee does this independently, but not for electric melters. Name is Ashok Chatwani 1-617-273-3189.

7. KTG Glassworks

"Joe" 1-412-366-0330

Physical modeling only.

8. Technical Committee \#21

Dr. W. Muschick, Chairman

SCHOTT Glaswerke Mainz

FAX 496131664012

Dr. Muschick is chairman of the ICG, TC 21 which is leading the round robin simulation tests for computer codes. TEMPEST results of the first test were submitted, but the final comparison results have not come in yet.

9. British Glass Technology

G.A.A. Goode, General Manager

Northumberland Road

Sheffield, S10 2UA

Phone (0742) 686201

Fax (0742) 681073

British Glass provides consulting services to the glass industry world-wide. They are also engaged in R\&D. British Glass has a CFD package which is used for glass modelling purposes. Judging from the available promotional information, it does not appear this is a major emphasis area of their work.

\section{Commercial Software}

1. TEMPEST

Pacific Northwest Laboratory

Richland, WA 99352

Don Trent (509)375-2105

Extensive melter modeling application and theory reports available to Loren Eyler/PNL and Mike Elliott/PNL. (Melter version of TEMPEST is not commercial software, but is available through PNL to DOE programs.) Most recent are HWVP Melter Performance Assessment reports (see References 1-3 which include references to earlier material).

2. CFDS FLOW-3D

AEA Technology, Computational Fluid Dynamics Services Pittsburgh, PA 15241

Contact was made with Ian Hawkins and Hari Doss (412) 833-4820. Promotional information was obtained. Referral was made to Dana Meissner of AEA (recently of OwensBrockway) who has used code for melter modeling (contact was not made). Users include Owens Brockway and Dow Corning (no other contact names provided). 


\section{FIDAP \\ Fluid Dynamics International \\ Evanston, IL 60201}

Contact was made with Lewis Collins (619-431-5130, Manager, Western Region, Carlsbad, CA). Promotional information received. Several technical application notes received. Contact with Fred Heard (Westinghouse Hanford Company) provided FIDAP Users and Theory Manual access. No direct user contacts made. Inn Choi at PNL had used FIDAP 4-5 years ago at the Savanna River Laboratory (SRL) to model DWPF. Grant Hawkes, Idaho National Engineering Laboratory (INEL) Senior Engineer (208-526-8767), has used to model electrically heated molten soil. Another contact: Peter Gottlieb, TWRS/Environmental Safety (702-794-5342) - contact not made.

\section{FLUENT \\ Fluent Incorporated \\ Lebonan, NH 03766}

Contact was made with Mary Kay Wieler (603-643-2600). Promotional information received along with technical discussion of radiation modeling basis, phase change basis, and Eulerian multi-phase model. Referred to Dr. Dipankar Choudhury, FLUENT Development manager and Dr. Xiaosong Wang at Libby-Owens-Ford (419-247-4218) who has work both the combustion and melt side of the furnace; also used PHOENICS, FLOW3D, and FIDAP codes contacts not made. Users include AirProducts, Corning, General Electric (melting but not glass).

\section{STAR-CD \\ ADAPCO \\ Melville, NY 11747}

Promotional information received from John Battaglioli (Manager, STAR-CD Agency Group, 313-453-2100). . No direct reference to melter application.

\section{CD 2000 \\ Adaptive \\ Huntsville, AL 35805}

Promotional information received from John Howell (Sales Engineer, 205-830-2620). No direct reference to melter applications. Referred to Dr. Peter Si (sp?), head of development.

\section{PATRAN (P/FLOTRAN) \\ PDA Engineering}

Contact made through hotline. Referred to Seattle office (206-641-7001) Keane Barthenheier, Jack Castro, Ed Jones. No contact made; no information received. Older (1991) FLOTRAN users manual available to Loren Eyler/PNL. 